\title{
Professional Distance and Social Work: stretching the elastic?
}

Rosemary Green, Raeleene Gregory \& Robyn Mason

\section{Key words:}

Professional boundaries, professional distance, social work profession

\begin{abstract}
Professional distance and the parallel concept of models of practice reliant on professional objectivity have been major platforms in professional education. In social work, these ideas are often seen as contentious, unreasonable and, in some cases unrealistic. Radical, feminist and rural social work approaches, for example, suggest that the expert role is not only inappropriate, but can be counter-productive and disrespectful of the people with whom we work. Postmodern approaches call for a deconstruction of professionalism in favour of context-specific partnerships between worker and client. How can workers ensure good, professional practice within a more flexible approach to professional distance and expertise? What are the issues and how may they be resolved? Are the boundaries of the professional relationship elastic, and if so, what are the consequences for practice, and the individual worker? This article explores the notion of flexible, elastic boundaries using literature and research from radical, postmodern, feminist and rural social work approaches.
\end{abstract}

\section{Introduction}


So long as the conduct of society depends upon special knowledge and competence, there will be an essential place for the professions. And so long as the professions are shaped by traditional models of knowledge and practice, neither the ideology nor the institutional reforms of the radical critics will eliminate the evils of expertise (Schon 1983, pp. 344-5).

Professional distance, professional boundaries and objectivity have been key concepts in education for many social and health professions. 'Professional objectivity was valued as the quality that allowed the helper to divorce him or herself from subjective feeling, attitudes and beliefs' (Shulman 1991, p. 15). However, radical, postmodern, feminist and rural social work approaches suggest that practice based on the 'expert' role is not only inappropriate, but can create unnecessary boundaries and unrealistic expectations. The professional expert role entailed workers distancing themselves from their clients in order to remain professionally objective. Maintaining professional distance may even be counterproductive to good practice in some situations (Fook 1993). Postmodern approaches to this dilemma seem more akin to the notion of partnership between social worker and client. Our explorations in this area led us to consider the ideas of professional distance and objectivity, the essential understanding of professional behaviour, and how we might move along a continuum of self-disclosure /exposure according to the particular context. Professional distance and professional boundaries, we believe, can be flexible and elastic, while still ensuring competent and appropriate practice. It may be useful to picture boundaries as a 'stretchy piece of elastic' or a 
continuum between the 'professional, objective expert' and the 'helpful friend' rather than the dichotomy of professional and non-professional that is often presented.

In this article, radical, postmodern, feminist and rural social work literature and research are used to explore this practice issue. There are strategies and supports to enable social workers to practice ethically and appropriately without the constraints of maintaining strict professional distance. Adopting a continuum model allows that it is possible for social workers to move along the spectrum, depending on their particular role, and using conscious judgement as to their place and how elastic the boundaries should be, at any given time.

In many contexts, the elasticity of such boundaries can facilitate effective and empowering relationships with the people with whom we come into contact, improving practice rather than detracting from it. The 'stretching' of the boundary or any movement along the continuum, should, however, stem from a conscious decision of the appropriateness of self-disclosure/ exposure, the protection of oneself, and good practice principles. It is also linked to concepts of self-reflection and reflexivity, but is perhaps an addition or extension to these skills and attributes.

\section{Professional objectivity and professionalism}

Understanding the notion of professionalism is a prelude to a discussion about professional objectivity and professional distance. Social work has struggled to 
identify with traditional forms of professionalism. Social work is unusual among aspirant professions in that a substantial section of the social work workforce has actively sought to develop an anti-professional stance (Macdonald 1995; Simpkin 1983). A desire to close the social distance between social worker and 'client', for example when taking a radical egalitarian stance (Healy 2000), is at the core of this perspective, along with an inherent mistrust of the way the relationship between the two is conceptualised (Lymberry 2000).

There has been a long-standing debate in social work about the benefits and disadvantages of pursuing a model of elite professionalism, and being equated with traditional professions such as medicine and law. A glance at a recently published Australian undergraduate social work text (Chenoweth \& McAuliffe 2005) provides some insight into current thinking about professionalism. In the second chapter the authors include a two-page section headed: 'The professionalisation of helping', where the history of the profession is detailed and the suggestion made that the current state may be one of 'deprofessionalisation'. The authors present the various contested views about social work's claims to be a profession, including its perceived lack of a sufficient evidence base and its opposition to elitism. The debate about the application of professionalism does not have a very high profile in this, or other general texts, and yet it is at the core of discussions about the 'deprofessionalisation' of social work that are currently occurring in Australia (Rosenthal 2005) and in other Western countries (Lymberry 2000). 
Social work has considered itself a profession in that it has codes of practice, regulation and accreditation of social work courses to maintain specialised knowledge and skills and ensure that principles of professional conduct are taught. The recognised benefits of professional status include a shared commitment to high practice standards and ethical behaviour, as well as the status to influence public policy and social change (Ife 1997, pp. 142-146). Camilleri (1999, p. 34) argues: 'Professionals are necessary. Consumers of services recognize the value and expertise of the professional'.

Professionalism, it has been argued, implies the acquisition of some form of specialism - knowledge and skills that are not possessed by untrained workers. Professionalism has been portrayed as emphasising technical proficiency, impartiality and, therefore, an apolitical approach (Mullaly 1993). It has been claimed that professionalism encourages the introduction of business-like career structures where 'correct' and 'professional' behaviour are highly prized. In this scenario, correct behavior, including detachment and controlled emotional involvement, is rewarded (Bailey \& Brake 1975). Professionalism has also been seen to support and reinforce the unequal distribution of power within traditional client/professional relationships (Healy 2000; Ife 1997; Weeks 1988).

The role of professional expert is well documented in individual work and clinical practice. The expert role relates to a positivist philosophy which holds that human behavior can be understood and studied objectively. It can be argued that social work can never be objective or value-neutral, and that it is 
always morally and politically charged. Indeed, Clark (2006) argues that social workers, like teachers and other human service professionals, cannot pretend to be neutral because of the nature of the contact, and the issues for work, with service users.

Furthermore, proponents of this belief contend that the expert approach follows certain laws and rules which enable the qualified social worker to 'prescribe' the suitable treatment or intervention. In this approach the social worker "becomes a skilled technician, who, understanding the "laws" can “intervene" appropriately to bring about change' (Ife 1997, p.45).

The continuing debate about regulation and registration of the profession in Australia attests to the concern held by some social workers about protecting their status and reinforcing their professional niche. Social work jargon acts to reinforce this 'specialism' and to create divisions between trained and untrained workers, and between social workers and service users. The language of the profession, using terms such as 'caseload', 'case notes', 'home visits', 'office interviews', and work with 'clients' or 'cases', has been seen to serve as a linguistic device to distance workers from citizens who are service users. In this environment, it is claimed, 'face-to-face contacts between human beings begin to take on the appearance of contact between things; terminology and language place a shield between worker and client' (Rojek, Peacock \& Collins 1998, pp. 37-38). It has also been argued that the development of professionalism has neutered the political aspects of the profession. In Mullaly's view: 
... professionalism emphasises technical aspects of helping, such as impartiality, emotional neutrality, and apolitical service. Thus, it masks the political component of social work practice and perpetuates the notion that capitalist social relations are natural and normal functions of an industrialised society (Mullaly 1993, p.192).

Proponents of the radical practice tradition mounted a critique of the expert model of social work practice and the move to professionalise social work. In their view, these developments were linked with

... a growing sense of distance between the worker and the client. This is expressed in several ways, e.g. the growth of jargon in the language of social workers; the restriction of access to clients in department buildings; the increasing importance of professional qualifications as a condition of employment and promotion in agencies; the development of a code of ethics to regulate practice. All of this, it is claimed, has driven a wedge between the worker and the client.... Moreover, by creating the basis for the monopolisation of power over standards of practice and control over entry into the profession, it can act as a drawbridge shutting out all new ideas and innovations which run counter to it (Rojek, Peacock \& Collins 1998, pp. 54-55). 
The structural analysis of personal problems inherent in the radical approach included a critique of the social control functions of the social work profession and welfare arrangements (Fook 1993, p. 7). Similarly, Leonard has argued:

Where there is welfare ... there is expertise directed to the organization and control (in their own interests) of those who are subject to its gaze (Leonard 1997, p. 99).

This approach also adopted earlier ideas from the anti-psychiatry movement, including rejection of the medical model of mental health practice and the professional distancing it implied (Fook 1993). In a discussion of 'objectivity' and 'self-determination', Fook states:

The rationale for professional objectivity may be the belief that clients are best helped by someone they see as a respected authority who is not emotionally involved with them. Like many functional myths, this has true and false components (Fook 1993 p. 61).

The effect, it is argued, may be that service users uncritically accept the views of the social worker, both because that is what they believe is expected of them, and because of the inherent power imbalance. A belief in selfdetermination ignores the fact that the professional usually has the power in the relationship, and that many service users are involuntary (Fook 1993). 
Models of practice have developed to address the perceived problems arising from the expert-professional tradition. These problems include the distancing of people using services, the unequal power relationships between workers and service users, divisions between qualified and unqualified workers, and the reinforcement of inequality in society resulting from an apolitical stance (Healy 2000). Approaches based on citizenship and partnership, for example, work towards developing democratic relationships between workers and service users (Camilleri 1999). Anti-oppressive and anti-discriminatory practice models also act to affirm a person's subjective experience and overcome professional distancing (Thompson 2001). They work to create equal relationships, and demystify processes involved in helping.

The impact of postmodern thinking on social work has contributed to these debates. Whereas the radical critique of professionalism focused on inequalities between professionals and service users, postmodern critiques strive to understand 'how professionalism maintains power relations through many levels of discourse' (Fook 2000, p. 104). In discussing empowerment and social work practice, Parker, Fook and Pease (1999, p. 153) argue that in a postmodern approach, clients are truly at the centre of decision-making about practice because they 'supply the interpretive framework' suited to a particular context. This approach directly challenges the positivist, truth-based tradition of expert professional knowledge. Postmodernists argue that the consequence of this new way of thinking about professionalism is not to simply discard the traditional ideas of professionalism but, rather, to reconfigure them to suit today's contexts. As Fook (2002, p.28) argues, 
professionalism 'must be reconceptualised as the ability to produce knowledge in ways which are applicable to specific settings'. This includes recognition of the ability to handle uncertainty and change, in situations where generalisation and prediction are less valid (Fook 2000; Fook, Ryan \& Hawkins 2000). In her approach to this challenge, Osmond (2005, p. 887) discusses how individuals make sense of knowledge 'according to the specific situation, circumstance, place and time in which they act '. Others refer to the way social workers act creatively and with flexibility to meet the context they face (Fook, Ryan \& Hawkins 2000; Merighi, Ryan, Renouf \& Healy 2005).

For our purposes, a key message from these practice approaches concerns the reduction of professional distance by increasing the use of self-disclosure and of seeing the relationship as a 'partnership'. Appropriate self-disclosure of positive and negative experiences, and sharing some aspects of one's own experience, enables the worker to be seen as a 'normal' person rather than a remote professional (Trevithick 2000). Judicious sharing of personal experience is connected to the concept of 'professional use of self', described as the use of the worker's personal manner and skills, including presence, to effect the best outcome for the client (McLellan 1995; Seden 1999). The use of self-knowledge and self-awareness 'involves the conscious employment of social work skills, knowledge, values and personal experience in ways that are illuminating to the work at hand' (Trevithick 2000, p. 83). Some researchers have been interested in how practitioners integrate professional knowledge and values with personal experience and emotions. Osmond (2005) includes personalised and historical knowledge, as well as practice wisdom, in her 
conceptualisation of how workers use knowledge in a particular practice situation. Findings reported from a study of clinicians indicated that the clinicians we interviewed did not appear to sacrifice rationality and objectivity in practicing compassionate care, but were able to balance "the head and the heart"' (Graber \& Mitcham 2004, p. 93).

The professional relationship, it is argued, is disciplined, and the self is used to help the service user. Brill (1995) explores the use of self in the professional relationship, where mutual trust and respect are key ingredients. She argues that the conscious use of self does not mean that interactions will be stiff or formal but rather that 'the best ones are warm and safe although not always comfortable' (Brill 1995, p. 96). Trevithick (2000) argues that there are two aspects of this 'use of self' idea - appropriate self-disclosure and the maintenance of professional boundaries. Echoing our earlier reference to a continuum, she explains:

In personal terms, it is where we take up an appropriate position of separateness while also maintaining a clear connection to service users, so that we are not too distant or inflexible on the one hand, nor too merged or inappropriately accommodating on the other (Trevithick 2000, p. 84).

Intuition is a related concept, and Trevithick recommends that further research is needed on the place of intuition in social work. In a contribution to this emerging field, an Australian study of the development of professional 
expertise found that expert practitioners made practice decisions intuitively, in accordance with the context and the situation (Fook, Ryan \& Hawkins, 2000). These ideas of self-knowledge, self-disclosure and intuition shed light on how social workers' thoughts and feelings interact with and complement their professional practice skills: the intersection of heart and head.

Our focus in this paper centres on two social work approaches, feminist practice and rural social work practice, that have actively addressed these issues and that reflect our own practice experience.

\section{Feminist approach}

Feminist practice in social work is underpinned by a feminist analysis of social arrangements, emphasising the recognition, acknowledgement and naming of women's experiences. This approach connects the personal and the political; it works to change oppressive social, economic and legal structures; and it challenges traditional ways of delivering services (see for example Dominelli \& McLeod 1989; Fook 1993; Marchant \& Wearing 1986; McLellan 1995; Weeks 1994, 2003). In a feminist approach, attention to detail such as furniture, colour, and comfort in interview settings, reception areas and waiting rooms can lessen the distance between workers and service users, encourage maximum sharing, and help demystify the helping process (Fook, 1993; McLeod 1994; Weeks 2004). In feminist practice, the power imbalance between worker and service user may be acknowledged and discussed. This achieves a more equal and non-authoritarian style, as well as being open with 
service users about possible interpretations of their situation. Feminist practitioners stress that feminist therapy is, first and foremost, a relationship between two women:

It is a relationship between two women who have come together for a clearly defined purpose and, when that purpose has been fulfilled, the relationship, as such, will be over. The roles are clear. The difference in power is clear, though not an issue (McLellan 1995, p. 172).

Feminist services in Australia developed in the 1970s, responding to women's dissatisfaction with traditional service models, including the dominance of the medical model, sexist attitudes towards women and other concerns such as the prevalence of mother-blaming in family welfare practice. The feminist critique included the negative impact on women of a professional belief in objectivity and neutrality, as Weeks outlined:

The hierarchical service or helping model supports a model of professionalism in which "experts" believe they should divorce their personal experiences, and certainly their lives, from the service users with whom they work. They should aim to be neutral, objective helpers - not noticing that their race, ethnicity, gender and personal experience must have an enormous impact on what they see and hear, how they think, what they consider evidence and what are the range of possible solutions they might propose (Weeks 1994, p. 64). 
In a feminist approach, personal problems are redefined using an analysis of oppression and understanding of power. This has helped women who have experienced abuse and oppression use their agency as women to develop a public voice to talk about their oppression and influence the way services are provided (Dominelli \& Mcleod, 1989). This political and public aspect of feminist practice faces resistance from policy makers, funding bodies and service managers, as well as professional bodies. Individual client throughput, for example, is more likely to be rewarded with funding, than public advocacy activities by workers in women's services.

The continuing feminist critique of professionalism includes recognition of the vested interest of professionals in controlling expert discourses and knowledge. In the area of violence against women, for example, the control of knowledge 'has relied on the suppression of the voice of the victim and a privileging of professional knowledge that mostly supports the cultural status quo and professional self-interest' (Breckenridge 1999 p. 15). In a reaction to this suppression, victim/ survivors are asking service providers to 'make more than cursory room for them at the table, to resist the urge to speak on their behalf and to dominate the space through which we carve our future agendas for change' (Keel, Fergus \& Heenan 2005, p. 12).

\section{Rural approach}

Similarities to the feminist approach of breaking down professional barriers can be found in the rural social work literature. The reality of living in a small community means that all members perform multiple roles (Cheers 1998; Lynn 
1993). Such role multiplicity in the rural practice context means a fusion of personal and professional lives. Major challenges for rural social workers include managing professional and personal role boundaries, and dual and multiple roles. Boundaries blur and roles overlap when professionals live and work in small communities. According to Mellow (2005, p. 50) professionalism is an urban concept and 'rural life problematizes the notion of professionalism'.

One Australian text has developed a different construction of social welfare practice by Aboriginal and Torres Strait Islander people, where the authors discuss deprofessionalisation, the 'Murri way' and the role of everyday helping of neighbours and 'resourceful friends' as follows:

In a deprofessional approach, friendship, yarning, recognition of your common humanity with the client, sharing of stories, sharing of self, including spirituality and humour, are recognised and valued techniques. A relationship characterised in this form works with power and equality in a more complex way than the present approaches within social and welfare work (Lynn, Thorpe \& Miles, with Cutts, Butcher \& Ford 1998, pp. 78-79).

The rural social worker is a neighbour and 'citizen in the community' and belongs to community groups and organisations both in her role as a social worker, and in her own right as a citizen. As rural communities feature dense social networks, professional and personal contacts are not necessarily discrete and separate. Additionally, role blurring occurs in rural practice due to a variety of contextual factors. In small organizations, positions are often multidimensional and generalist and flexibility of staff is required. There is an expectation that 'if it needs doing.... do it', often meaning that social workers 
extend their roles into areas not formally recognized in their position descriptions or indeed covered by agency funding agreements (Cheers 1998, 1999; Krieg Mayer 2001). Sometimes other staff extend their boundaries into the province of what would usually be the 'territory' of the social worker. This blurring can have positive outcomes, where staff work with their strengths and acknowledge each other's specific expertise, but it can create additional stresses (Dollard, Winefield \& Winefield 1999).

Role blurring and the experience of dual and multiple roles is not necessarily a 'bad thing', but can be constructed as both a challenge and as a positive experience for the worker and community members. It is maintained that 'rural contexts pose unique challenges for practitioners in constructing professional identity and the need for active negotiation with clients about roles in small communities' (Lewis 2001 p. 110). Active negotiation is a useful construct and appears to be commonly practised in rural social work:

In fact when (rural social workers) are working with clients they often have to share information of how they can act if their clients see them in public at places like Woolworths, the hotel, or many other venues. The general rule is social workers will not acknowledge their clients until they are acknowledged (Munn \& Munn 2003, p. 24)

Rural workers negotiate availability and privacy on a daily basis. Rural communities can have different expectations from urban communities of what is considered private or semi-private and where these boundaries, social and 
psychological, are drawn (Pugh 2000). The rural social worker is identified as both a professional with expertise, and a member of the community (individual, partner, parent, group member and so on). The resultant high levels of visibility in the community are perceived by some authors as an asset which may lead to increased confidence of community members, and by others as problematic (Cheers 1998; Ginsberg 1998; Lewis 2001; Lonne 1990). While some workers struggle with lack of privacy, others enjoy the recognition and respect. It appears that the high visibility of the rural social worker, socially and professionally, leads to greater informality in their professional persona, and this can often improve outcomes for service users, but it can also be problematic.

In rural areas, there is both an expectation that some personal information will be publicly known (and that this may be much more information than would be known in an urban environment) and caution about exposing too much as it will have ramifications for a long period, particularly in small, relatively stable populations (Pugh 2000). Living, working, raising a family and being highly visible in one's work role can create some concerns for rural social workers around safety and security (Green, Gregory \& Mason 2003). Anecdotally, rural workers have commented, in conversation variously with the authors, that feelings of acceptance, alienation, visibility, scrutiny, and belonging change over time, depending on the circumstances, the relationships involved, and the length of time in the community. Lonne (1990) also noted that changes over time were experienced by workers, which he conceptualised as stages of adjustment to rural practice. 
How do rural social workers, highly visible in their communities, active members of the community in many roles, juggle the notion of appropriate exposure? Not only do we have extensive knowledge about at least some of our clients - as a rural worker said to one of us recently: 'When someone walks in the door for counselling, even without having met them before, I have heaps of information about them from other people, working with other people and in other contexts' - they also have extensive knowledge about us as social workers and community members. How much self-disclosure is appropriate or at least not redundant? How can a sound professional relationship be established in these circumstances?

\section{Implications for Practice}

Our experience suggests that there are many similarities between feminist and rural social work approaches, especially in the areas of professional distance and boundaries. We agree with Mermelstein (1991) when she relates her experience of a synergy between feminist and rural practice.

We are interested to explore further how workers decide which point on the continuum is the most appropriate for the situation at hand. Are these decisions conscious or intuitive? Are the skills needed to make these decisions part of the toolkit that social workers acquire by the time they graduate, or do they develop, with practice wisdom and experience, over time? 
Exploring our own feminist and rural practice experience, we analysed some examples where we chose different points on the professional distance continuum, according to the practice demands placed on us. As women working with women, we could think of many instances where a professionally distant stance would have been quite inappropriate, including working with homeless women, young pregnant women and women surviving violence. In our contact with other professionals in the sexual assault field, for example, we could think of occasions where, in order to assist a woman in crisis, we needed to advocate on her behalf with the police. On some of these occasions we deliberately chose the distant point of the continuum, where formality and technical expertise were required to achieve the result. At these times there was a requirement to advocate an opposing view or to pursue directions on the woman's behalf with which the police may have disagreed. Similar situations may arise when required to appear in court as an expert witness or in a statutory role in juvenile justice. At other times we may choose to loosen the elastic and reveal more of ourselves to the other professionals involved, to ensure a just outcome for our client. In a rural area especially, we are likely to know the police and other professionals, in both their professional and their other roles. How realistic is it to be distant with people (clients and other workers) who are known to us in other contexts?

Rather than clarity, we are left with more challenging questions. What are the factors that affect the decision about the social worker's location on the continuum? Our experience suggests that the decision about where to stand 
on the continuum is a deliberate, conscious, professional one. It may be that when we have to be more assertive we choose the distant, expert mode. Do we choose a more 'relaxed' way of operating when we feel more comfortable, that is, when we are working with people who do not threaten us, such as other women, community groups and other rural people? Are we more inclined to be professionally distant in situations where we think it is expected of us, perhaps with men in authority, funding bodies, the medical profession or the police? Does the level of discomfort or confidence that we feel indicate where on the continuum we will stand?

\section{Conclusion}

This paper has explored the notion of professional distance and the idea of professional objectivity in the light of radical, postmodern, feminist and rural social work critiques. Conceptualisations of professional distance suggest to us that, rather than operating at polar opposites (either objective expert or friend), the experienced practitioner moves along a continuum between each stance to meet the demands of the particular context. The elasticity of the continuum allows the worker to move along it, depending on the uniqueness of each practice situation. We have suggested that workers make deliberate decisions as to how much distance they will maintain between themselves and their clients, and themselves and other professionals. More research and exploration of these issues, building on the existing studies of professional expertise, are needed if we are to discern how these skills are acquired (Fook, Ryan \& Hawkins 2000; Merighi, Ryan, Renouf \& Healy 2005). Developing a 
reflective approach to practice and access to good supervision appear to be essential ingredients in the development of this kind of professional mastery. Continuing education of practitioners, using their own varied practice experiences, will assist in developing the practice wisdom that is one of the core components at the heart of this approach (Osmond 2005).

If the decision to move along the continuum is a conscious, professional one (and we believe that it is), made with due regard to social work ethics and values, then good practice can occur at any point. 


\section{References}

Bailey R \& Brake M (eds.), (1975), Radical Social Work, Edward Arnold, London

Breckenridge J (1999), Subjugation and silences: the role of the professions in silencing victims of sexual and domestic violence.In Breckenridge, J \& Laing L (eds.), Challenging Silence: Innovative responses to sexual and domestic violence, Allen \& Unwin, Sydney, pp. 6-30

Brill N (1995), Working with People: The helping process, Fifth Edition, Longman, White Plains.

Camilleri P (1999), Social work and its search for meaning: Theories, narratives and practices. In Pease, B. \& Fook, J. (eds.), Transforming Social Work Practice, Allen \& Unwin, Sydney, pp.25-39.

Cheers B (1998), Welfare Bushed: Social care in rural Australia, Ashgate, Aldershot.

Cheers B (1999), Community embedded rural social care practice. In Briskman, L. \& Lynn, M. (eds.), Challenging rural practice, Deakin University Press, Geelong, pp. 92-102.

Chenoweth L \& McAuliffe D (2005), The Road to Social Work and Human Service Practice: An Introductory Text, Thomson, Melbourne Clark C (2006) Moral Character in Social Work, British Journal of Social Work, $36,75-89$.

Dollard M, Winefield H. \& Winefield A. (1999), Burnout and Job Satisfaction in Rural and Metropolitan Social Workers, Rural Social Work, Vol. 4, April, 33-43. 
Dominelli L \& McLeod E (1989), Feminist Social Work, Macmillan, Basingstoke.

Fook J (1993), Radical Casework: A theory of practice, Allen \& Unwin, Sydney.

Fook, J (2000) Deconstructing and reconstructing professional expertise. In B Fawcett, B Featherstone, J Fook \& A Rossiter (eds.), Practice and Research in Social Work: Postmodern feminist perspectives, Routledge, London, Chapter 6, pp. 104-119.

Fook J (2002), Social Work: Critical Theory and Practice, Sage Publications, London.

Fook J, Ryan M \& Hawkins L (2000), Professional Expertise: Practice, theory and education for working in uncertainty, Whiting \& Birch Ltd., London.

Ginsberg L (1998), Social Work in Rural Communities, Council on Social Work Education, $2^{\text {nd }}$ Edition, Alexandria, VA, USA.

Graber D \& Mitcham M (2004), Compassionate Clinicians, Holistic Nursing Practice, (March/April), 87-94.

Green R, Gregory R \& Mason R (2003), It's no picnic: personal and family safety for rural social workers, Australian Social Work, Vol. 56, No. 2, June, 94-106.

Healy K (2000), Social Work Practices: Contemporary Perspectives on Change, Sage Publications, London.

Ife J (1997), Rethinking Social Work, Addison Wesley Longman, Melbourne.

Keel M, Fergus L \& Heenan M. (2005), Home Truths: A conference in review, Issues, No. 3, March, Australian Centre for the Study of Sexual Assault, $1-55$ 
Krieg Mayer A. (2001), Rural Social Work: The perceptions and experiences of five remote practitioners, Australian Social Work, Vol. 54, No. 1, 91102.

Leonard P (1997), Postmodern Welfare: Reconstructing an emancipatory project, Sage Publications, London.

Lewis I (2001), Social workers' strategies for living and working in small communities. In V. Mansel Lees (ed). Building Bridges, Conference Proceedings of the $5^{\text {th }}$ Rural Social Work Action Group National Conference, Beechworth, 2001, Beechworth, Rural Social Work Action Group,

Lonne R (1990), Beginning Country Practice, Australian Social Work, Vol. 43, No. 1, March, 31-39.

Lymberry M (2000), The Retreat from Professionalism. In N. Malin (ed), Professionalism, Boundaries and the Workplace, Routledge, London, pp. 123-138.

Lynn M (1993), Network-Enhancing Practice, Rural Social Work, Vol. 1, December, 3-23.

Lynn R, Thorpe R \& Miles D. with Cutts C, Butcher A. \& Ford L (1998), Murri Way: Aborigines and Torres Strait Islanders reconstruct social welfare practice, James Cook University, Townsville.

Macdonald KM (1995), The sociology of the professions, Thousand Oaks, London.

McLellan B (1995), Beyond Psychoppression: A Feminist Alternative Therapy, Spinifex, Melbourne. 
McLeod E (1994), Women's Experience of Feminist Therapy and Counselling, Open University Press, Buckingham.

Marchant H \& Wearing B (eds.), (1986), Gender reclaimed: women in social work, Hale \& Iremonger, Sydney.

Mellow M (2005), The work of rural professionals: doing the gemeinschaftgesellschaft gavotte. Rural Sociology, 70 (1) 50-69.

Merighi J, Ryan M, Renouf N \& Healy B (2005), Reassessing a Theory of Professional Expertise: A Cross-National Investigation of Expert Mental Health Social Workers, British Journal of Social Work, 35, 709-725.

Mermelstein J (1991) Feminist Practice in Rural Social Work. In M. BrickerJenkins, N. Hooyman,\& N. Gottlieb (eds.), Feminist Social Work Practice in Clinical Settings, Sage, Newbury Park, pp. 150-171.

Mullaly R (1993), Structural Social Work: Ideology, theory and practice, McClelland \& Stewart, Toronto.

Munn P \& Munn T (2003), Rural Social Work: Moving Forward, Rural Social Work, Vol.13 (1), 22-34.

Osmond J (2005), The Knowledge Spectrum: A Framework for Teaching Knowledge and its Use in Social Work Practice, British Journal of Social Work, 35, 881-900

Parker S, Fook J \& Pease B (1999), Empowerment: The modernist social work concept par excellence. In B. Pease \& J. Fook (eds.) Transforming Social Work Practice: Postmodern critical perspectives, Allen \& Unwin, St Leonards, Chapter 10, pp. 150-157.

Pugh R (2000), Rural Social Work, Russell House Publishing, London.

Rojek C, Peacock G \& Collins S (1998), Social Work and Received Ideas, Routledge, London. 
Rosenthal H (2005), The deprofessionalisation of Social Workers, AASW National Bulletin, 16 (1) 15.

Schon D (1983), The Reflective Practitioner: How Professionals Think in Action, Basic Books,

Shulman L (1991), Interactional Social Work Practice, FE Peacock Publishers Inc, Itasca.

Seden J (1999), Counselling Skills in Social Work Practice, Open University Press, Buckingham.

Simpkin M (1983), Trapped within welfare: surviving social work, Macmillan, London.

Thompson N (2001), Anti-discriminatory Practice, Third Edition, Palgrave, Basingstoke

Trevithick P (2000), Social Work Skills: a practice handbook, Open University Press, Buckingham

Weeks W (1988), De-Professionalisation or a New Approach to Professionalism? Australian Social Work, Vol. 41, No.1, March, 29-37 Weeks W (1994), Women Working Together: Lessons from Feminist Women's Services, Longman Cheshire, Melbourne

Weeks W (2003), Women: Developing feminist practice in women's services. In J. Allan, B. Pease \& L. Briskman (eds.), Critical Social Work: An Introduction to Theories and Practices, Allen \& Unwin, Sydney, pp. 107123

Weeks W (2004), Creating attractive services which citizens want to attend, Australian Social Work Vol. 57, No. 4, December, 319-330 